\title{
Pengaruh Motivasi Dan Budaya Organisasi Terhadap Kinerja Karyawan Pada PT. Fenixindo Global Mandiri (Veneta System)
}

\author{
${ }^{1}$ Mulyadi, Prayogo Wicaksono \\ Dosen Fakultas Ekonomi Universitas Pamulang \\ ${ }^{1}$ Email : dosen00031@unpam.ac.id
}

\begin{abstract}
ABSTRAK
Tujuan pada penelitian ini adalah untuk mengetahui pengaruh motivasi dan budaya organisasi terhadap kinerja karyawan pada PT. Fenixindo Global Mandiri (Veneta System).

Metode yang digunakan adalah metode deskriptif dengan pendekatan asosiatif. Teknik sampling yang digunakan adalah proporsional random sampling menggunakan dengan sampel sebanyak 50 responden. Analisis data menggunakan analisis regresi, analisis koefisien korelasi, analisis koefisien determinasi dan uji hipotesis

Hasil penelitian ini adalah motivasi berpengaruh positif dan signifikan terhadap kinerja karyawan dengan persamaan regresi $\mathrm{Y}=13,290+0,660 \mathrm{X} 1$, nila koefisien korelasi 0,690 dan koefisien determinasi sebesar 47,6\%. Uji hipotesis diperoleh $\mathrm{t}$ hitung $>\mathrm{t}$ tabel atau $(6,600>2,011)$. Budaya organisasi berpengaruh positif dan signifikan terhadap kinerja karyawan $(\mathrm{Y})$ dengan persamaan regresi $\mathrm{Y}$ $=15,604+0,613 \mathrm{X} 2$ nilai koefisien korelasi 0,651 dan koefisien determinasi sebesar $42,4 \%$. Uji hipotesis diperoleh $t$ hitung $>\mathrm{t}$ tabel atau $(5,944>2,011)$ Motivasi dan budaya organisasi berpengaruh positif dan signifikan terhadap kinerja karyawan dengan persamaan regresi $Y=8,726+0,444 X 1+0,339 X 2$. Nilai koefisien korelasi diperoleh sebesar 0,744 artinya variabel bebas dengan variabel terikat memiliki pengaruh yang kuat dengan koefisien determinasi atau pengaruh secara simultan sebesar 55,4\% sedangkan sisanya sebesar 44,6\% dipengaruhi faktor lain. Uji hipotesis diperoleh nilai $\mathrm{F}$ hitung $>\mathrm{F}$ tabel atau $(29,214>2,800)$, hal tersebut juga diperkuat dengan probability signifikansi $0,000<0,05$. Dengan demikian H0 ditolak dan $\mathrm{H} 3$ diterima. Artinya terdapat pengaruh positif dan signifikan secara simultan antara motivasi dan budaya organisasi terhadap kinerja karyawan di PT. Fenixindo Global Mandiri (Veneta System)..
\end{abstract}

Kata Kunci : Motivasi, Budaya organisasi, Kinerja Karyawan. 


\section{PENDAHULUAN}

\section{A. Latar Belakang Masalah}

Analisis terhadap motivasi dan budaya organisasi, memiliki nilai yang amat strategis. Informasi mengenai kinerja karyawan dan faktor-faktor yang ikut berpengaruh terhadap kinerja karyawan tersebut sangat penting untuk diketahui sebagai suatu kegiatan evaluasi untuk menilai atau melihat keberhasilan dan kegagalan pelaksanaan tugas dan fungsi yang dibebankan kepadanya. Pada tataran inilah motivasi, dan budaya organisasi karyawan, menjadi suatu hal penting yang perlu mendapat perhatian karena perbaikan kinerja birokrasi memiliki implikasi yang luas dalam kehidupan masyarakat, terutama dalam memperbaiki tingkat kepercayaan masyarakat kepada pemerintah. Rendahnya motivasi karyawan dan budaya organisasi karyawan selama ini menjadi salah satu faktor penting yang mendorong munculnya krisis kepercayaan masyarakat.

Di dalam sebuah perusahaan karyawan tidak hanya membutuhkan motivasi melainkan harus memiliki budaya organisasi untuk melalukan tugas yang diberikan perusahaan. Untuk melihat kondisi awal proses budaya organisasi di PT. Fenixindo Global Mandiri (Veneta System), maka penulis melakukan pra survey budaya organisasi terhadap 50 orang karyawan secara rata-rata proses budaya organisasi yang ada di PT. Fenixindo Global Mandiri (Veneta System) yaitu 75\% masih belum mencapai dari standar $100 \%$, utamanya dalam
Orientasi Tim. Dapat disimpulkan target budaya organisasi di PT. Fenixindo Global Mandiri (Veneta System) belum mencapai standar.

Kinerja adalah hasil dari suatu proses yang mengacu dan diukur selama periode waktu tertentu berdasarkan ketentuan atau kesepakatan yang telah ditetapkan sebelumnya. Penilaian kinerja merupakan suatu proses organisasi untuk menilai kinerja karyawannya. Tujuan dilakukannya penilaian kinerja secara umum adalah untuk memberikan umpan balik kepada karyawan dalam upaya memperbaiki kinerjanya dan meningkatkan produktivitas organisasi, khususnya yang berkaitan dengan kebijaksanaan terhadap karyawan seperti untuk tujuan promosi, kenaikan gaji, pendidikan dan latihan.

Organisasi haruslah memilih kriteria secara subyektif maupun obyektif . Kriteria kinerja secara obyektif adalah evaluasi kinerja terhadap standar-standar spesifik, sedangkan ukuran secara subyektif adalah seberapa baik seorang karyawan bekerja keseluruhan. Untuk melihat kondisi kinerja karyawan PT. Fenixindo Global Mandiri (Veneta System), nilai pekerja yang ada di PT. Fenixindo Global Mandiri (Veneta System) adalah 70,00 \% dari standar bobot terutama dalam kesesuain pelaksanaan tugas dan tanggung jawab memiliki presentase yang paling menjauhi bobot standar dibandingkan kualitas dan kuantitas kerja. Jadi, dapat disimpulkan bahwa target standar kinerja karyawan di PT. 
Fenixindo Global Mandiri (Veneta System) semuanya belum mencapai standar.

\section{B. Identifikasi Masalah}

Berdasarkan latar belakang penelitian, maka dapat diidentifikasi masalahnya yaitu:

1. Kurangnya promosi jabatan karyawan di PT. Fenixindo Global Mandiri (Veneta System).

2. Masih rendahnya penghargaan yang diberikan pemimpin kepada karyawan yang telah mencapai target yang diberikan di PT. Fenixindo Global Mandiri (Veneta System).

3. Tingkat kerjasama tim/orientasi tim kurang kompak dalam mencapai tujuan perusahaan di PT. Fenixindo Global Mandiri (Veneta System).

4. Karyawan tidak mencapai target dalam melaksanakan tugas yang sudah diberikan oleh perusahaan di PT. Fenixindo Global Mandiri (Veneta System).

5. Kurangnya tanggung jawab karyawan terhadap tugasnya di PT. Fenixindo Global Mandiri (Veneta System).

\section{Rumusan Masalah}

Adapun

rumusan

masalahnya adalah:

1. Apakah ada pengaruh motivasi terhadap kinerja karyawan (Y) di PT. Fenixindo Global Mandiri (Veneta System)?

2. Apakah ada pengaruh budaya organisasi terhadap kinerja karyawan (Y) di PT. Fenixindo Global Mandiri (Veneta System)?

3. Apakah ada pengaruh motivasi dan budaya organisasi terhadap kinerja karyawan (Y) secara simultan di PT. Fenixindo Global Mandiri (Veneta System)?

\section{TINJAUAN PUSTAKA}

\section{A. Motivasi}

Motivasi berasal dari kata "movere" yang berarti dorongan atau menggerakan. Motivasi dalam manajemen hanya ditunjukan kepada sumber daya manusia umumnya dan khususnya untuk para bawahan atau pengikut. Dalam organisasi, motivasi sangat di perlukan sebagai salah satu hal untuk mencapai tujuan yang telah ditetapkan oleh lembaga. Motivasi merupakan keinginan, hasrat motor penggerak dalam diri manusia, motivasi berhubungan dengan faktor psikologi manusia yang mencerminkan antar sikap, kebutuhan dan kepuasan yang terjadi pada diri manusia sedangkan daya dorong yang berasal dari luar diri seseorang ditumbuhkan oleh pimpinan. Pentingnya motivasi karena motivasi adalah hal yang menyebabkan, menyalurkan, dan mendukung prilaku manusia supaya mau bekerja sama secara giat sehingga mencapai hasil yang optimal.

Menurut Prabu Mangku Negara (2002 : 95), mengatakan mengenai motivasi adalah kondisi yang berpengaruh membangkitkan, mengarahkan dan memelihara prilaku yang berhubungan dengan lingkungan kerja. Menurut Malayu S.P. Hasibuan (2016 : 219) Motivasi adalah pemberian daya gerak yang menciptakan kegairahan kerja 
seseorang agar mereka mau bekerja sama, bekerja efektif dan integerasi dengan segala upayanya untuk mencapai kepuasan.

Dari pendapat diatas penulis dapat mengambil kesimpulan bahwa motivasi merupakan suatu proses dimana manusia di dorong untuk melakukan aktivitas yang disebabkan manusia mempunyai kebutuhan yang harus dipenuhi.

\section{B. Budaya Organisasi}

Budaya Organisasi adalah sebuah sistem makna bersama yang dianut oleh para anggota yang membedakan suatu organisasi dari organisasiorganisasi lainnya. Menurut Rivai dan Mulyadi (2012:373), bahwa "Pengertian budaya menurut definisi, budaya itu sukar dipahami, tidak berwujud, implisit dan dianggap sudah semestinya atau baku. Definisi lain menyebutkan budaya adalah sejumlah pemahaman penting seperti norma, nilai, sikap, dan keyakinan yang dimiliki bersama oleh anggota organisasi." Menurut Laudon dan Laudon (2012:97), bahwa "Organisasi adalah struktur formal yang stabil dan formal yang mengambil sumber daya dari lingkungan dan memprosesnya untuk menciptakan output". Dari penggabungan 2 kata yaitu budaya dan organisasi, maka menjadi budaya organisasi yang memiliki definisi atau arti tersendiri. Menurut Robbins dan Judge (2014), bahwa "Kultur organisasi (organizational culture) mengacu pada sebuah sistem makna bersama yang dianut oleh para anggota yang membedakan organisasi tersebut dengan organisasi lainnya".

Menurut Rivai dan Mulyadi (2012:374), menyatakan bahwa "Budaya organisasi adalah suatu kerangka kerja yang menjadi pedoman tingkah laku sehari-hari dan membuat keputusan untuk karyawan dan mengarahkan tindakan mereka untuk mencapai tujuan organisasi". Menurut Laudon dan Laudon (2012:100), bahwa "Budaya organisasi adalah kekuatan pengikat yang kuat yang menghambat konflik politik dan mendorong pemahaman yang sama, perjanjian pada prosedur, dan praktik umum". Menurut Tintami Leslie et al (2012:3), bahwa: Budaya organisasi adalah filosofi dasar organisasi yang memuat keyakinan, norma-norma, dan nilai-nilai bersama yang menjadi karekteristik inti tentang bagaimana melakukan sesuatu dalam organisasi. Keyakinan, norma-norma, dan nilai-nilai tersebut menjadi pegangan semua sumber daya manusia dalam organisasi dalam melaksanakan kinerjanya (Wibowo, 2011:19)."maka dapat ditarik sebuah kesimpulan bahwa "budaya organisasi adalah suatu nilai-nilai yang diyakini (belief) dan merupakan sistem dalam suatu organisasi yang mendukung dalam pelaksanaan kegiatan dalam berorganisasi yang mempunyai ciri-ciri tertentu untuk mencapai tujuan yang telah disepakati bersama".

\section{Kinerja}

Suatu organisasi, baik itu pemerintah maupun swasta, selalu digerakan oleh sekelompok orang 
yang berperan aktif untuk mencapai tujuan yang ingin dicapai dari organisasi tersebut. Tujuan organisasi tentunya tidak akan tercapai jika kinerja anggota atau pegawainya tidak maksimal. Menurut Mangkunegara (2013) dalam Pasolong (2010:176) kinerja merupakan hasil kerja secara kualitas dan kuantitas yang dicapai oleh seseorang dalam melaksanakan fungsinya sesuai dengan tanggungjawab yang diberikan kepadanya. Tidak jauh berbeda, Siagian (2016) mendefinisikan kinerja sebagai suatu keseluruhan kemampuan seseorang untuk bekerja sedemikian rupa sehingga mencapai tujuan kerja secara optimal dan berbagai sasaran yang telah diciptakan dengan pengorbanan yang secara rasio lebih kecil dibandingkan dengan hasil yang dicapai.
Prawirosentono dalam Pasolong (2014) lebih cenderung menggunakan kata performance dalam menyebut kata kinerja. Menurutnya performance atau kinerja adalah hasil yang dapat dicapai oleh seseorang atau sekelompok orang dalam suatu organisasi, sesuai dengan tanggungjawab masing-masing dalam rangka mencapai tujuan organisasi bersangkutan secara legal, tidak melanggar hukum dan sesuai dengan moral maupun etika. Berbagai pendapat diatas dapat menggambarkan bahwa kinerja pegawai dan kinerja organisasi memiliki keterkaitan yang sangat erat, tercapainya tujuan organisasi tidak bisa dilepaskan dari sumber daya yang dimiliki oleh organisasi yang digerakan atau dijalankan pegawai yang berperan aktif sebagai pelaku dalam upaya mencapai tujuan organisasi.

\section{Kerangka Berpikir}

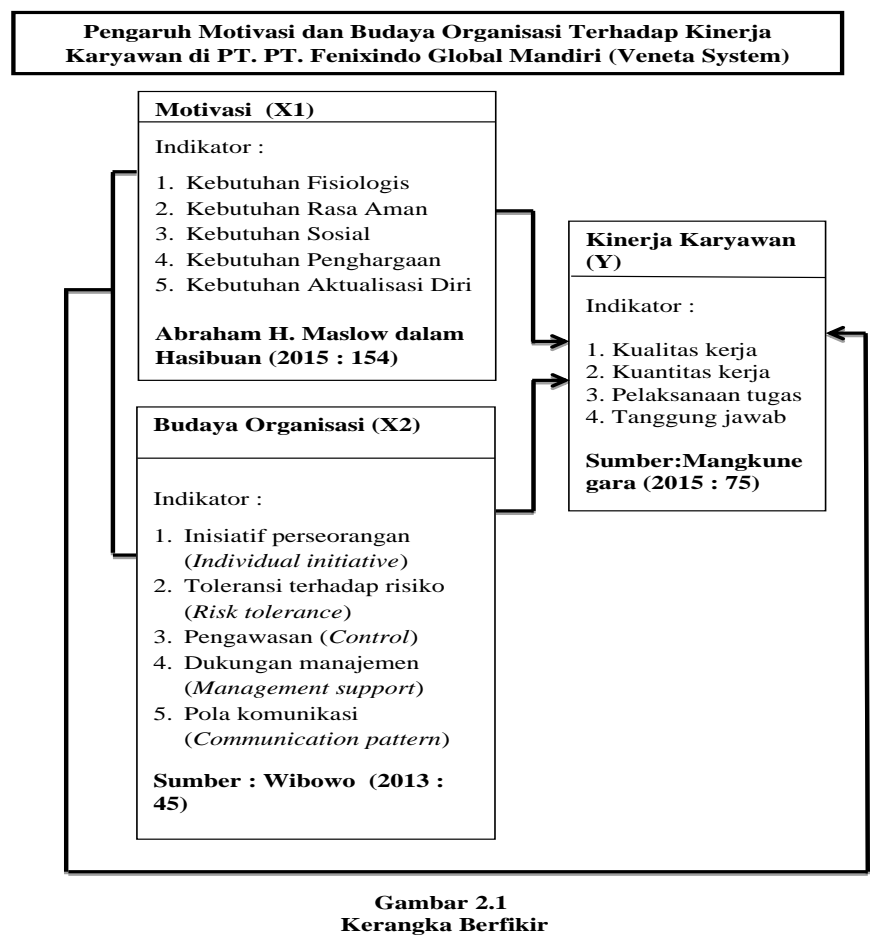




\section{E. Hipotesis}

Berdasarkan kerangka pemikiran yang telah dikemukakan dan dilandasi kajian teori sebelumnya, maka hipotesis pada peneliitian ini dapat dirumuskan sebagai berikut:

$\mathrm{H}_{1}=$ Terdapat pengaruh positif dan signifikan antara motivasi $\left(\mathrm{X}_{1}\right)$ terhadap kinerja karyawan $(\mathrm{Y})$.

$\mathrm{H}_{2}=$ Terdapat pengaruh positif dan signifikan antara budaya organisasi $\left(\mathrm{X}_{2}\right)$ terhadap kinerja karyawan $(\mathrm{Y})$.

$\mathrm{H}_{3}=$ Terdapat pengaruh positif dan signifikan antara motivasi $\left(\mathrm{X}_{1}\right)$ dan budaya organisasi $\left(\mathrm{X}_{2}\right)$ terhadap kinerja karyawan (Y) secara simultan.

\section{METODE PENELITIAN}

Penelitian ini dilaksanakan di PT. Fenixindo Global Mandiri (Veneta System) di alamat: Jl. Abdul Muis No.68, RT.4/RW.3, Petojo Sel., Kecamatan Gambir, Kota Jakarta
Pusat, Daerah Khusus Ibukota Jakarta 10160. Jenis penelitian ini adalah deskriptif kuantitatif, populasi karyawan PT. Fenixindo Global Mandiri (Veneta System) yang berjumlah 50 karyawan teknik pengambilan sample menggunakan sample jenuh yaitu seluruh populasi dijadikan sampel

Metode pengumpulan data menggunakan data primer yaitu observasi dan penyebaran kuesioner serta data sekunder yaitu dokumentasi dan studi kepustakaan, uji instrumen penelitian menggunakan uji validitas dan uji reliabilitas, uji asumsi klasik, dalam penelitian ini uji asumsi klasik yang digunakan adalah meliputi: uji normalitas, uji multikolinearitas, uji autokorelasi, dan uji heterokedastisitas.

Metode analisis data menggunakan analisis deskriptif, adapun tahapan analisis yang dilakukan adalah analisis regresi linier sederhana dan linier berganda, analisis koefisien korelasi (R), analisis koefisien determinasi $(R$ Square), pengujian hipotesis

\section{HASIL PENELITIAN}

\section{Uji Validitas Instrumen.}

Tabel 4.1

Hasil Uji Validitas

\begin{tabular}{|c|c|c|c|c|c|}
\hline Item Kuesioner & r hitungMotivasi & $\begin{array}{c}\text { r hitung Budaya } \\
\text { Organisasi }\end{array}$ & r hitung Kinerja & r tabel & Keputusan \\
\hline 1. & 0.482 & 0.447 & 0.546 & 0.279 & Valid \\
\hline 2. & 0.557 & 0.461 & 0.625 & 0.279 & Valid \\
\hline 3. & 0.507 & 0.434 & 0.420 & 0.279 & Valid \\
\hline 4. & 0.486 & 0.448 & 0.724 & 0.279 & Valid \\
\hline 5. & 0.376 & 0.462 & 0.322 & 0.279 & Valid \\
\hline 6. & 0.477 & 0.486 & 0.633 & 0.279 & Valid \\
\hline 7. & 0.516 & 0.669 & 0.530 & 0.279 & Valid \\
\hline 8. & 0.579 & 0.544 & 0.492 & 0.279 & Valid \\
\hline 9. & 0.695 & 0.630 & 0.370 & 0.279 & Valid \\
\hline 10. & 0.374 & 0.595 & 0.324 & 0.279 & Valid \\
\hline
\end{tabular}


Berdasarkan data tabel di atasdiperoleh nilai $r$ hitung $>r$ tabel 0.279, dengan demikian maka semua item kuesioner dinyatakan valid. Untuk itu kuesioner yang digunakan layak untuk diolah sebagai data penelitian

2. Uji Reliabilitas Instrumen.

Tabel 4.2

Hasil Uji Reliabilitas Variabel Independen dan Dependen

\begin{tabular}{|l|l|c|c|l|}
\hline No. & Variabel & $\begin{array}{c}\text { Coeficient } \\
\text { Alpha }\end{array}$ & $\begin{array}{c}\text { Standar } \\
\text { Chronbach } \\
\text { Alpha }\end{array}$ & Keputusan \\
\hline 1 & $\begin{array}{l}\text { Motivasi } \\
\text { (X1) }\end{array}$ & 0.671 & 0.600 & Reliabel \\
\hline 2 & $\begin{array}{l}\text { Budaya } \\
\text { organisasi } \\
\text { (X2) }\end{array}$ & 0.694 & 0.600 & Reliabel \\
\hline 3 & $\begin{array}{l}\text { Kinerja } \\
\text { Karyawan } \\
\text { (Y) }\end{array}$ & 0.667 & 0.600 & Reliabel \\
\hline
\end{tabular}

Sumber: Data Primer diolah.

Berdasarkan

hasil pengujian pada tabel di atas, menunjukkan bahwa variabel motivasi $\left(\mathrm{X}_{1}\right), \quad$ budaya organisasi $\left(\mathrm{X}_{2}\right)$ dan kinerja karyawan (Y) dinyatakan reliabel, hal itu dibuktikan dengan masing-masing variabel memiliki nilai coeficien Alpha lebih besar dari Chronbath Alpha 0,600.

3. Pengujian Asumsi Klasik (Uji Prasyarat Data)

a. Uji Normalitas

Tabel 4.3

Hasil Uji Normalitas Dengan Kolmogorov-Smirnov Test Tests of Normality KolmogorovSmirnova Shapiro-Wilk Statist $\quad$ Statist $\mid$ Sig

\begin{tabular}{ll|r|r|r|r|r} 
& ic & df & Sig. & \multicolumn{1}{c|}{ ic } & df & . \\
\hline Kinerja & .094 & 5 & .20 & .984 & 5 & .70 \\
\hline Karyaw & & 0 & $0^{*}$ & & 0 & 9
\end{tabular}
Karyaw an $(Y)$

${ }^{*}$. This is a lower bound of the true significance.

a. Lilliefors Significance Correction

Sumber: Data Primer diolah.

Berdasarkan hasil pengujian pada tabel di atas, diperoleh nilai signifikansi $\alpha=$ 0,200 dimana nilai tersebut lebih besar dari nilai $\alpha=0,050$ atau $(0,200>0,050)$. Dengan demikian maka asumsi distribusi persamaan pada uji ini adalah normal.

b. Uji Multikolinearitas

Tabel 4.4

Hasil Pengujian Multikolinearitas Dengan Collinearity Statistic Kinerja Karyawan Sebagai Variabel Dependen

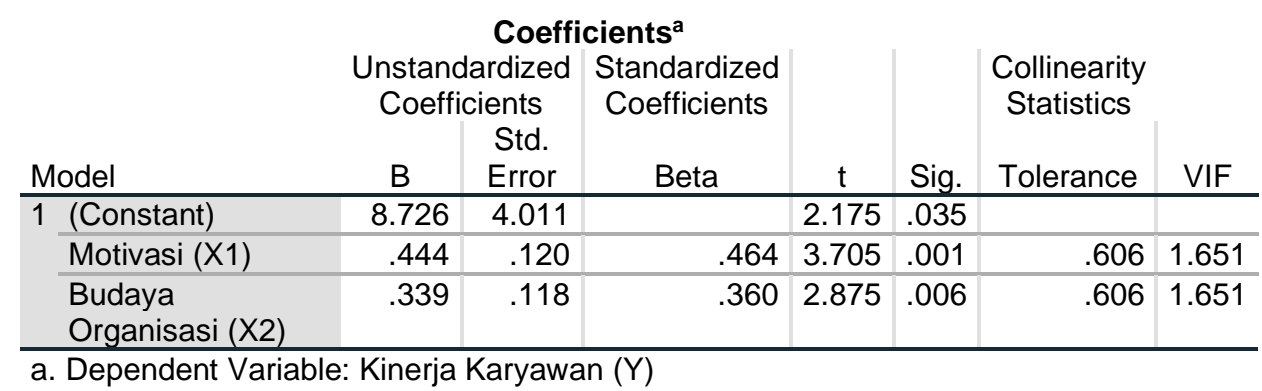

Berdasarkan hasil pengujian multikolinieritas pada tabel di atas diperoleh nilai tolerance masing- masing variabel bebas yaitu motivasi sebesar 0,606 dan budaya organisasi sebesar 0,606, dimana kedua nilai 
tersebut kurang dari 1, dan nilai Variance Inflation Factor (VIF) variabel motivasi sebesar 1,651 serta budaya organisasi sebesar 1,651 dimana nilai tersebut kurang dari 10. Dengan demikian model regresi ini tidak ada multikolinearitas.

\section{c. Uji Autokorelasi}

\section{Tabel 4.5}

Uji Durbin-Watson

\begin{tabular}{cc|c|c|c|c} 
& & \multicolumn{9}{c}{ Model Summary } & & \\
& & & Std. & \\
& & $R$ & Adjusted & Error of & \\
Model & $R$ & Square & Square & the & Durbin- \\
\hline & & Estimate & Watson \\
\hline
\end{tabular}

\begin{tabular}{ll|l|l|l|l}
\hline 1 & $.744^{\mathrm{a}}$ & .554 & .535 & 2.490 & 2.150 \\
\hline
\end{tabular}

a. Predictors: (Constant), Budaya Organisasi (X2),

Motivasi (X1)

b. Dependent Variable: Kinerja Karyawan (Y)

Sumber: Data Primer diolah.

Berdasarkan hasil pengujian pada tabel di atas, model regresi ini tidak ada autokorelasi, hal ini dibuktikan dengan nilai Durbin-Watson sebesar 2.150 yang berada diantara interval $1.550-2.460$.

d. Uji Heteroskedastisitas Tabel 4.6

Hasil Pengujian Heteroskesdastisitas

Dengan Uji Glejser

Coefficients $^{a}$

\begin{tabular}{|c|c|c|c|c|c|}
\hline \multirow[b]{2}{*}{ Model } & \multicolumn{2}{|c|}{$\begin{array}{l}\text { Unstandardized } \\
\text { Coefficients }\end{array}$} & \multirow{2}{*}{$\begin{array}{c}\text { Standardized } \\
\text { Coefficients } \\
\text { Beta }\end{array}$} & \multirow[b]{2}{*}{$t$} & \multirow[b]{2}{*}{ Sig. } \\
\hline & 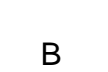 & $\begin{array}{l}\text { Std. } \\
\text { Error }\end{array}$ & & & \\
\hline 1 (Constant) & 6.127 & 2.556 & & 2.397 & .021 \\
\hline $\begin{array}{l}\text { Motivasi } \\
\text { (X1) }\end{array}$ & -.018 & .076 & -.043 & -.235 & .816 \\
\hline $\begin{array}{l}\text { Budaya } \\
\text { Organisasi } \\
\text { (X2) }\end{array}$ & -.094 & .075 & -.226 & $1.245^{-}$ & .219 \\
\hline
\end{tabular}

a. Dependent Variable: RES2

Sumber: Data Primer diolah.

Berdasarkan hasil pengujian pada tabel di atas, glejser test model pada variabel motivasi $\left(\mathrm{X}_{1}\right)$ diperoleh nilai probability signifikansi (Sig.) sebesar 0,816 dan budaya organisasi $\left(\mathrm{X}_{2}\right)$ diperoleh nilai probability signifikansi (Sig.) sebesar 0,219 dimana keduanya nilai signifikansi (Sig.) > 0,05. Dengan demikian regression model pada data ini tidak ada gangguan

heteroskesdastisitas, sehingga model regresi ini layak dipakai sebagai data penelitian.

\section{Analisis Deskriptif dan Verifikatif}

1. AnalisisDeskriptif Karakteristik Responden

\section{a. Karakteristik Responden} Berdasarkan Jenis Kelamin

Tabel 4.7

Karakteristik Responden

Berdasarkan Jenis Kelamin Jenis Kelamin

Valid Cumulative Frequency Percent Percent Percent

\begin{tabular}{c|r|r|r|r|r}
\hline Valid Laki-laki & 29 & 58.0 & 58.0 & 58.0 \\
\hline Perempuan & 21 & 42.0 & 42.0 & 100.0 \\
\hline Total & 50 & 100.0 & 100.0 & \\
\hline
\end{tabular}

Sumber: Data primer diolah.

Berdasarkan data di atas, responden yang berjenis kelamin laki-laki sebanyak 29 orang atau $58,0 \%$, sedangkan yang berjenis kelamin perempuan sebanyak 21 orang atau $42,0 \%$.

b. Karakteristik Responden Berdasarkan Usia

Tabel 4.8

Karakteristik Responden

Berdasarkan Usia Usia

Valid Cumulative 
JENIUS

\begin{tabular}{|l|r|r|r|r}
\hline Valid $\begin{array}{l}17-25 \\
\text { Tahun }\end{array}$ & 12 & 24.0 & 24.0 & 24.0 \\
\hline $\begin{array}{l}26-35 \\
\text { Tahun }\end{array}$ & 15 & 30.0 & 30.0 & 54.0 \\
\hline $\begin{array}{l}\text { 36-45 } \\
\text { Tahun }\end{array}$ & 14 & 28.0 & 28.0 & 82.0 \\
\hline $\begin{array}{l}\text { > } 45 \\
\text { Tahun }\end{array}$ & 9 & 18.0 & 18.0 & 100.0 \\
\hline Total & 50 & 100.0 & 100.0 & \\
\hline
\end{tabular}

Sumber: Data primer diolah.

Data di atas, responden yang berusia antara 17-25 tahun sebanyak sebanyak 12 orang atau $24,0 \%$, yang berusia antara 26-35 tahun sebanyak 15 orang atau $30,0 \%$, yang berusia antara 36-45 tahun sebanyak 14 orang atau $28,0 \%$ dan yang berusia $>45$ tahun sebanyak 9 orang atau $18,0 \%$.

c. Karakteristik Responden Berdasarkan Pendidikan

Tabel 4.9

Karakteristik Responden

Berdasarkan Pendidikan

Pendidikan

Valid Cumulative

Frequency Percent Percent Percent

\begin{tabular}{|c|c|c|c|c|c|}
\hline Valid & SLTA & 21 & 42.0 & 42.0 & 42.0 \\
\hline & Diploma & 8 & 16.0 & 16.0 & 58.0 \\
\hline & $\begin{array}{l}\text { Sarjana } \\
\text { (S1) }\end{array}$ & 17 & 34.0 & 34.0 & 92.0 \\
\hline & $\begin{array}{l}\text { Pasca } \\
\text { Sarjana } \\
\text { (S2) }\end{array}$ & 4 & 8.0 & 8.0 & 100.0 \\
\hline & Total & 50 & 100.0 & 100.0 & \\
\hline
\end{tabular}

Sumber: Data primer diolah.

Berdasarkan data di atas, responden yang berpendidikan SLTA sebanyak 21 orang atau 42,0\%, berpendidikan Diploma sebanyak 8 orang atau 16,0\%, yang berpendidikan S1 sebanyak 17 orang atau $34,0 \%$, dan yang berpendidikan S2 sebanyak 4 orang atau 8,0\%. d. Karakteristik Responden Berdasarkan Lama Bekerja

Tabel 4.10

Karakteristik Responden

Berdasarkan Lama Bekerja Lama Bekerja

Valid Cumulative Frequency Percent Percent Percent

\begin{tabular}{|l|r|r|r|r}
\hline Valid $\begin{array}{l}<2 \\
\text { Tahun }\end{array}$ & 13 & 26.0 & 26.0 & 26.0 \\
\hline $\begin{array}{l}\text { 3-6 } \\
\text { Tahun }\end{array}$ & 12 & 24.0 & 24.0 & 50.0 \\
\hline $\begin{array}{l}7-10 \\
\text { Tahun }\end{array}$ & 12 & 24.0 & 24.0 & 74.0 \\
\hline $\begin{array}{l}>10 \\
\text { Tahun }\end{array}$ & 13 & 26.0 & 26.0 & 100.0 \\
\hline Total & 50 & 100.0 & 100.0 & \\
\hline
\end{tabular}

Sumber: Data primer diolah.

Data di atas, responden yang bekerja $<2$ tahun sebanyak 13 orang atau $26,0 \%$, yang bekerja antara 3-6 tahun sebanyak 12 orang atau $24,0 \%$, yang bekerja antara 7-10 tahun sebanyak 12 orang atau $24,0 \%$ dan yang telah bekerja > 10 tahun sebanyak 13 orang atau $26,0 \%$.

2. Analisis Deskriptif Penilaian Responden Variabel

Tanggapan responden atas pernyataan pada variabel motivasi diperoleh rata-rata skor 3.93 termasuk pada rentang skala 3,40-4,19 dengan kriteria baik. Responden yang menjawab sangat setuju dan setuju sebesar $71,8 \%$ dan responden yang menjawab ragu dan tidak setuju mencapai $28,2 \%$.

Tanggapan responden pada variabel budaya organisasi diperoleh ratarata skor 3.86 termasuk pada 
rentang skala 3,40-4,19 dengan kriteria baik. Responden yang menjawab sangat setuju dan setuju sebesar $66,6 \%$ dan responden yang menjawab ragu dan tidak setuju mencapai $33,4 \%$.

Tanggapan responden variabel kinerja karyawan diperoleh rata-rata skor sebesar 3.93 termasuk pada rentang skala 3,40-4,19 dengan kriteria baik. Responden yang menjawab sangat setuju dan setuju sebesar $70,6 \%$ dan responden yang menjawab ragu dan tidak setuju mencapai $29,4 \%$.

\section{Analisis Verifikatif}

a. Analisis Regresi Linier.

Tabel 4.11

Hasil Pengujian Regresi Berganda Variabel Motivasi $\left(X_{1}\right)$ dan Budaya organisasi $\left(\mathbf{X}_{3}\right)$ Terhadap Kinerja

Karyawan (Y)

Coefficients $^{a}$

Unstandardized Standardized

Coefficients Coefficients

\begin{tabular}{l|r|r|r|r|r} 
Model & $\mathrm{B}$ & \multicolumn{1}{|c|}{$\begin{array}{l}\text { Std. } \\
\text { Error }\end{array}$} & \multicolumn{1}{|c|}{ Beta } & \multicolumn{1}{c}{$\mathrm{t}$} & Sig. \\
\hline 1 (Constant) & 8.726 & 4.011 & & 2.175 & .035 \\
\hline $\begin{array}{l}\text { Motivasi } \\
\text { (X1) }\end{array}$ & .444 & .120 & .464 & 3.705 & .001 \\
$\begin{array}{l}\text { Budaya } \\
\begin{array}{l}\text { Organisasi } \\
\text { (X2) }\end{array}\end{array}$ & .339 & .118 & .360 & 2.875 & .006 \\
\hline $\begin{array}{l}\text { a. Dependent Variable: Kinerja Karyawan (Y) } \\
\text { Sumber: Data Primer diolah. }\end{array}$
\end{tabular}

Berdasarkan hasil analisis perhitungan regresi pada tabel di atas, maka dapat diperoleh persamaan regresi $\mathrm{Y}=8,726+0,444 \mathrm{X}_{1}$ $+0,339 \mathrm{X}_{2}$. b. Analisis Koefisien Korelasi (r).

Tabel 4.12

Hasil Analisis Koefisien Korelasi Secara Simultan Antara Motivasi $\left(\mathbf{X}_{1}\right)$ dan Budaya organisasi $\left(\mathbf{X}_{2}\right)$ Terhadap Kinerja Karyawan (Y) Model Summary ${ }^{b}$

\begin{tabular}{|c|c|c|c|c|}
\hline \multirow[b]{2}{*}{ Model } & \multirow[b]{2}{*}{$\mathrm{R}$} & & \multirow[b]{2}{*}{$\begin{array}{l}\text { Std. Error of the } \\
\text { Estimate }\end{array}$} \\
\hline & & $\begin{array}{c}\mathrm{R} \\
\text { Square }\end{array}$ & $\begin{array}{c}\text { Adjusted } \\
\text { R } \\
\text { Square }\end{array}$ & \\
\hline 1 & $.744^{\mathrm{a}}$ & .554 & .535 & 2.490 \\
\hline \multicolumn{5}{|c|}{$\begin{array}{l}\text { a. Predictors: (Constant), Budaya Organisasi (X2), Motivasi } \\
\text { (X1) }\end{array}$} \\
\hline $\begin{array}{l}\text { b. Depe } \\
\text { Sumber: }\end{array}$ & dent V & ariable: Ki & neria Karva & \\
\hline
\end{tabular}

Berdasarkan pada hasil pengujian pada tabel di atas, diperoleh nilai $R$ (koefisien korelasi) sebesar 0,744 artinya variabel motivasi $\left(\mathrm{X}_{1}\right)$ dan budaya organisasi (X2) mempunyai tingkat pengaruh atau hubungan yang kuat terhadap kinerja karyawan (Y).

c. Analisis Koefisien Determinasi ( $R$ Square). Tabel 4.13

Hasil Analisis Koefisien

Determinasi Secara Simultan

Antara Variabel Motivasi $\left(\mathbf{X}_{1}\right)$ dan Budaya organisasi (X2)Terhadap Kinerja Karyawan

(Y)

Model Summary ${ }^{b}$

\begin{tabular}{lc|c|c|c} 
Model & $\mathrm{R}$ & $\begin{array}{c}\mathrm{R} \\
\text { Square }\end{array}$ & $\begin{array}{c}\text { Adjusted } \\
\mathrm{R} \\
\text { Square }\end{array}$ & $\begin{array}{c}\text { Std. Error } \\
\text { of the } \\
\text { Estimate }\end{array}$ \\
\hline 1 & $.744^{\mathrm{a}}$ & .554 & .535 & 2.490 \\
\hline a. Predictors: (Constant), Budaya Organisasi \\
(X2), Motivasi (X1) \\
b. Dependent Variable: Kinerja Karyawan (Y)
\end{tabular}
Sumber: Data Primer diolah.

Berdasarkan pada hasil pengujian pada tabel di atas, diperoleh nilai $R$-square 
sebesar 0,554 maka dapat disimpulkan bahwa variabel motivasi $\left(\mathrm{X}_{1}\right)$ dan budaya organisasi (X2) berpengaruh terhadap variabel kinerja karyawan (Y) sebesar 55,4\% sedangkan sisanya sebesar $44,6 \%$ dipengaruhi oleh faktor lain yang tidak dilakukan penelitian.

d. Pengujian Hipotesis.

1) Pengujian Hipotesis Secara Parsial (Uji t). (a)Pengaruh Motivasi (X) Terhadap Kinerja Karyawan (Y).

Tabel 4.14

Hasil Uji Hipotesis (Uji t) Variabel

Motivasi $\left(\mathbf{X}_{1}\right)$ Terhadap Kinerja

Karyawan (Y)

Coefficients $^{a}$

Unstandardized Standardized

Coefficients Coefficients

\begin{tabular}{|c|c|c|c|c|c|}
\hline Model & $\mathrm{B}$ & $\begin{array}{l}\text { Std. } \\
\text { Error }\end{array}$ & Beta & $\mathrm{t}$ & Sig. \\
\hline 1 (Constant) & 13.290 & 3.953 & & 3.362 & .002 \\
\hline $\begin{array}{l}\text { Motivasi } \\
(\mathrm{X} 1)\end{array}$ & .660 & .100 & .690 & 6.600 & .000 \\
\hline
\end{tabular}

Berdasarkan pada hasil pengujian pada tabel di atas diperoleh nilai $t_{\text {hitung }}>t_{\text {tabel }}$ atau $(6,600>2,011)$ Hal tersebut juga diperkuat dengan nilai $\rho$ value < Sig.0,05 atau $(0,000<0,05)$. Dengan demikian maka $\mathrm{H}_{0}$ ditolak dan $\mathrm{H}_{1}$ diterima, hal ini menunjukkan bahwa terdapat pengaruh positif dan signifikan secara parsial antara motivasi terhadap poduktivitas kerja karyawan pada PT. Fenixindo Global Mandiri (Veneta System). (b) Pengaruh Dsiplin Kerja (X2) Terhadap Kinerja Karyawan (Y) Tabel 4.15

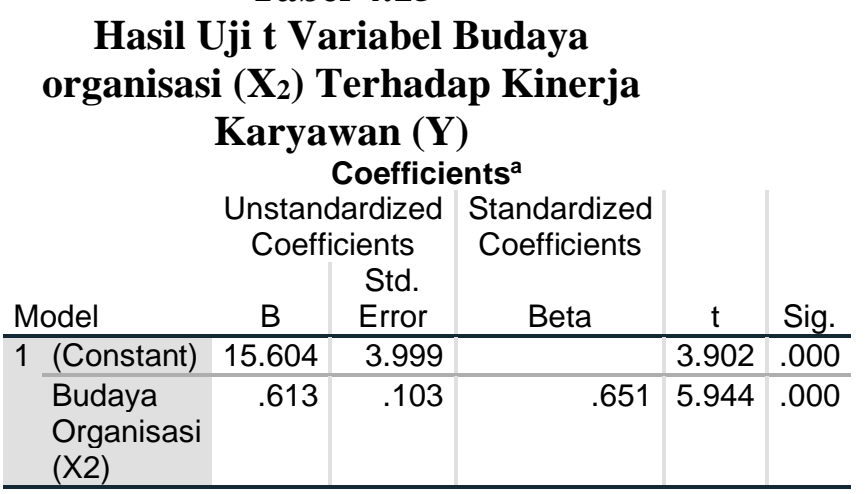

a. Dependent Variable: Kinerja Karyawan (Y)

Sumber: Data Primer diolah

Berdasarkan

pada hasil pengujian pada tabel di atas diperoleh nilai $t_{\text {hitung }}>$ $t$ tabel atau $(5,944>$ 2,011). Hal tersebut juga diperkuat dengan nilai $\rho$ value $<$ Sig. 0,05 atau $(0,000<0,05)$. Dengan demikian maka $\mathrm{H}_{0}$ ditolak dan $\mathrm{H}_{2}$ diterima, hal ini menunjukkan bahwa terdapat pengaruh yang positif dan signifikan secara parsial antara budaya organisasi terhadap kinerja karyawan pada PT. Fenixindo Global Mandiri (Veneta System). 
2) Pengujian Hipotesis Secara Simultan (Uji F). Tabel 4.16

Hasil Hipotesis (Uji F) Secara

Simultan Antara Motivasi (X1) dan Budaya organisasi (X2)

Terhadap Kinerja Karyawan (Y) ANOVA $^{\mathrm{a}}$

\begin{tabular}{|c|c|c|c|c|c|c|}
\hline \multirow{2}{*}{\multicolumn{2}{|c|}{ Model }} & \multicolumn{4}{|c|}{ S } & \multirow[b]{2}{*}{ Sig. } \\
\hline & & $\begin{array}{l}\text { Sum of } \\
\text { Squares }\end{array}$ & df & $\begin{array}{l}\text { Mean } \\
\text { Square }\end{array}$ & $F$ & \\
\hline \multirow[t]{3}{*}{1} & Regression & 362.238 & 2 & 181.119 & 29.214 & $.000^{\mathrm{b}}$ \\
\hline & Residual & 291.382 & 47 & 6.200 & & \\
\hline & Total & 653.620 & 49 & & & \\
\hline
\end{tabular}

a. Dependent Variable: Kinerja Karyawan (Y)

Predictors: (Constant), Budaya Organisasi (X2), Motivasi (X1)

$$
\text { pada hasil }
$$

pengujian pada tabel di atas diperoleh nilai $F$ hitung > F tabel atau $(29,214>2,800)$, hal ini juga diperkuat dengan $\rho$ value < Sig. 0,05 atau $(0,000<$ 0,05). Dengan demikian maka $\mathrm{H}_{0}$ ditolak dan $\mathrm{H}_{3}$ diterima, hal ini menunjukkan bahwa terdapat pengaruh positif dan signifikan secara simultan antara motivasi dan budaya organisasi terhadap kinerja karyawan pada PT. Fenixindo Global Mandiri (Veneta System).

\section{KESIMPULAN DAN SARAN}

\section{A. Kesimpulan}

Berdasarkan uraian pada bab-bab sebelumnya, dan dari hasil analisis serta pembahasan mengenai pengaruh motivasi dan budaya organisasi terhadap kinerja karyawan, sebagai berikut :
1. Motivasi $\left(\mathrm{X}_{1}\right)$ berpengaruh positif dan signifikan terhadap kinerja karyawan (Y) dengan persamaan regresi $Y=13,290+$ $0,660 X_{1}$, nila koefisien korelasi sebesar 0,690 artinya kedua variabel memiliki pengaruh yang kuat dengan koefisien determinasi sebesar $47,6 \%$. Uji hipotesis diperoleh $\mathrm{t}$ hitung $>\mathrm{t}$ tabel atau $(6,600>2,011)$, hal ini diperkuat dengan probability signifikansi $0,000<$ 0,05, dengan demikian $\mathrm{H}_{0}$ ditolak dan $\mathrm{H}_{1}$ diterima artinya terdapat pengaruh positif dan signifikan antara motivasi terhadap kinerja karyawan di PT. Fenixindo Global Mandiri (Veneta System).

2. Budaya organisasi $\left(\mathrm{X}_{2}\right)$ berpengaruh positif dan signifikan terhadap kinerja karyawan (Y) dengan persamaan regresi $\mathrm{Y}=15,604+$ $0,613 X_{2}$ nilai koefisien korelasi sebesar 0,651 artinya kedua memiliki pengaruh yang kuat dengan koefisien determinasi sebesar $42,4 \%$. Uji hipotesis diperoleh $\mathrm{t}$ hitung $>\mathrm{t}$ tabel atau $(5,944>2,011)$, hal ini diperkuat dengan probability signifikansi $0,000<0,05$, dengan demikian $\mathrm{H}_{0}$ ditolak dan $\mathrm{H}_{2}$ diterima artinya terdapat pengaruh positif dan signifikan antara budaya organisasi $\left(\mathrm{X}_{2}\right)$ terhadap kinerja karyawan (Y) di PT. Fenixindo Global Mandiri (Veneta System).

3. Motivasi $\left(\mathrm{X}_{1}\right)$ dan budaya organisasi $\left(\mathrm{X}_{2}\right)$ berpengaruh positif dan signifikan terhadap kinerja karyawan (Y) dengan persamaan regresi $\mathrm{Y}=8,726+$ 
$0,444 X_{1}+0,339 X_{2}$. Nilai koefisien korelasi diperoleh sebesar 0,744 artinya variabel bebas dengan variabel terikat memiliki pengaruh yang kuat dengan koefisien determinasi atau pengaruh secara simultan sebesar $55,4 \%$ sedangkan sisanya sebesar $44,6 \%$ dipengaruhi faktor lain. Uji hipotesis diperoleh nilai $F$ hitung $>F_{\text {tabel }}$ atau $(29,214>2,800)$, hal tersebut juga diperkuat dengan probability signifikansi $0,000<0,05$. Dengan demikian $\mathrm{H}_{0}$ ditolak dan $\mathrm{H}_{3}$ diterima. Artinya terdapat pengaruh positif dan signifikan secara simultan antara motivasi dan budaya organisasi terhadap kinerja karyawan di PT. Fenixindo Global Mandiri (Veneta System).

\section{B. Saran}

1. Variabel motivasi (X1) pernyataan yang paling lemah adalah perusahaan mengakui dan menghargai hasil kerja karyawannya, dimana hanya mencapai score sebesar 3,82. Untuk lebih baik lagi perusahaan harus menuntun karyawan yang kesulitan dan memberikan apresiasi kepada karyawan yang mencapai target

2. Variabel budaya organisasi (X2), pernyataan yang paling lemah adalah karyawan selalu mampu memberikan ide kreatif untuk kemajuan perusahaan, dimana hanya mencapai score sebesar 3,74. Untuk lebih baik lagi perusahaan harus lebih mendorong karyawan untuk memiliki kreativitas dalam menghasilkan kinerja yang lebih baik lagi

3. Variabel kinerja karyawan (Y), pernyataan yang paling lemah adalah Skill yang saya miliki sesuai dengan pekerjaan yang saya kerjakan, dimana hanya mencapai score sebesar 3,80. Untuk lebih baik lagi perusahaan harus mengasah kemampuan karyawan agar dapat menunjang tujuan organisasi dengan lebih baik lagi.

\section{DAFTAR PUSTAKA}

$\begin{array}{lr}\text { Enrico Maramis. } & \text { (2013). } \\ \text { Kepemimpinan, } & \text { Budaya } \\ \text { Organisasi, Dan } & \text { Motivasi } \\ \text { Pengaruhnya } & \text { Terhadap } \\ \text { Kinerja Karyawan } & \text { Pada PT. } \\ \text { Bank Tabungan Negara } \\ \text { (Persero) Cabang Manado. } \\ \text { Jurnal EMBA: Jurnal Riset } \\ \text { Ekonomi, Manajemen, Bisnis } \\ \text { dan Akuntansi. Vol 1. No.4. } \\ \text { Tahun 2013.ISSN : 2303 - } \\ \text { 1174. }\end{array}$

Handoko. (2014). Manajemen

Personalia Dan Sumber Daya

Manusia. Yogyakarta: BPFEYogyakarta.

Hariandja, M. T. (2012). Manajemen Sumber Daya Manusia. Jakarta: Grasindo.

Harry Murti ,Veronika Agustini Srimulyani (2013).Pengaruh Motivasi Terhadap Kinerja Pegawai Dengan Variabel Pemediasi Kepuasaan Kerja Pada PDAM Kota Madiun.JRMA Jurnal Riset Manajemen dan Akuntansi.Vol. 1. No. 1 Tahun 2013. 
Hasibuan, M. (2016). Manajemen Sumber Daya Manusia. Jakarta: PT. Bumi Aksara.

Ida Ayu Brahmasari, Agus Suprayetno. (2008). Pengaruh Motivasi Kerja, Kepemimpinan dan Budaya Organisasi Terhadap Kepuasan Kerja Karyawan serta Dampaknya pada Kinerja Perusahaan (Studi kasus pada PT. Pei Hai International Wiratama Indonesia).Jurnal Manajemen dan Kewirausahaan. Vol. 10. No. 2. Tahun 2008. ISSN: 1411-1438.

Jackson, R. L., \& Mathis, J. H. (2011). Manajemen Sumber Daya Manusia. Jakarta: Salemba Empat.

Mangkunegara, A. P. (2013). Manajemen Sumber Daya Manusia Perusahaan. Bandung: Rosdakarya.

Marwansyah. (2010). Manajemen Sumber Daya Manusia, Edisi Kedua. Bandung: Alfabeta.

Maslow, A. H. (2010). Motivation and Personality. Jakarta: Rajawali.

Nawawi, H. (2010). Kepemimpinan yang Efektif . Yogyakarta: Gajah Mada Unisity Press.
Robbins, S. P. (2010). Perilaku Organisasi. Jakarta: Salemba Empat.

Siagian, S. P. (2016). Manajemen Sumber Daya Alam. Jakarta: Bumi Aksara.

Sugiyono. (2010). Metode Penelitian Bisnis. Jakarta: CV. Alfabeta.

Sunarsi, D. (2017). Pengaruh Disiplin, Motivasi, Dan Kompetensi Terhadap Prestasi Belajar (Studi Kasus Pada Mahasiswa Universitas Pamulang, Tangerang Selatan Tahun Akademik 2016-2017). Jurnal Mandiri, 1(2), 207-226.

Sunarsi, D., \& Yuliani, I. (2019). Pengaruh Gaya Kepemimpinan Dan Budaya Organisasi Terhadap Kinerja Karyawan Pada Bank BTN Kantor Cabang Tangerang. Jurnal Semarak, 2(1).

Thoha, M. (2010). Perilaku Organisasi, Konsep Dasar Aplikasinya. Jakarta: CV. Rajawali.

Wibowo. (2014). Manajemen Kinerja (Edisi Keempat). Jakarta: Raja Grafindo Persada. 